断层泥石英颗粒外表具有各种形态，其 中多数颗粒呈棱角状和次棱角状，而少数颗 粒是圆状和次圆状. 通常, 在沂沭断裂带的 断层泥中棱角状颗粒常与次棱角状、次圆状 石英混杂在一起. 由此表明, 该断裂带在不 同时期经历了几次构造活动.

沂沭断裂带断层泥石英颗粒另一特征是 在其表面具有机械破裂、撞击标志和化学溶 蚀形貌. 这些表面结构是: 1. 普遍具有贝壳 状断口、平行阶步、痕和 V 型坑. 2. 有时具 有河流花样破裂、平行长擦䅦和株形坑. 3 . 断层泥中部分石英颗粒表面具有不同程度的 溶蚀现象. 因而按照石英的表面特点可将它 们分为四类. 据沂沭断裂带四条断层中 19 个断层泥石英样品表面形貌的测试数据综合 表示如下:

\begin{tabular}{|c|c|}
\hline 断 & 石英颗柆表面结构类型 \\
\hline F、（部-葛沟断层） & II, III \\
\hline F, (沂水-汤头断层) & II, IV \\
\hline$F_{2}$ (白芬子一浮来山断层) & I \\
\hline F (昌邑-大店断层) & 1,11 \\
\hline
\end{tabular}

由此表明, 断层泥石英颗粒表面结构可
以反映沂沭断裂带活动的历史和分析它们破 裂的方式: 圆状与次圆状石英是缓慢碾磨作 用的结果. : 贝壳状断口和平行阶步显示了石 英在强应力下的挤压破裂. 棱角状和次棱角 状颗粒、河流花样破裂、平行长徖槽、大 $\mathrm{V}$ 形 坑和楔形坑是沿断层快速错动和机械撞击产 生的.

断层泥石英颗柆表面结构, 尤其是溶蚀. 现象, 反映了断层自形成或开始活动时至现 今所经历的时间. 按照类型 I 到 IV 的顺 序, 石英颗粒表面溶蚀程度增加, 那么这一顺 序应表示出断层从新到老的活动次序. I 类 石英约在全新世或更晚一段时间形成，II 类 约在晚更新世形成, III 类约在中更新世形 成,而 IV 类约在早更新世形成.

综上所述, 沂沭断裂带属于长期活动的 断裂带, 而在其东部的 $F_{2}$ 断层显示具最强. 的活动性, 它是全新世以来一直活动的断层, 1668 年莒县一郯城大地震与该断层的构造活. 动密切相关.

\author{
（中国科学院地质确究所, 北京) \\ 姚新 \\ （国家地震局地球物理研究所，北京）
}

\title{
电磁辐射对大豆体内微量元素含量及 细胞亚显微结构影响的研究
}

本文通过实验研究了电磁辐射对大豆生 长的影响. 发现, 高能量密度的电磁辐射改 变了大豆从土壤中吸收微量元素的能力, 并 引起了大豆植株细胞亚显微结构的改变.

我们采用 $2-25 \mu$ 的特定电磁辐射器与 辐射波段相近的红外辐射器对发芽过程中的 大豆进行了不同条件的处理.

对处理后的大豆样品进行了光谱分析, 检测其体内 $\mathrm{Cu}, \mathrm{Fe}, \mathrm{Zn}, \mathrm{Cr}, \mathrm{Mo}$ 等微量元素 的含量。分析结果发现与对照组比较,经过特 定电磁辐射与红外辐射处理的样品均不同程
度的调整了大豆体内微量元素的含量. 不同 的微量元素有不同的最佳调节条件. 最佳调. 节条件要由辐射器材料、辐射波长范围与辐 射照度综合决定.

在所进行的实验范围内, 大豆体内 $\mathrm{Fe}$ 与 $\mathrm{Zn}$ 元素含量的最佳调节条件是相近的, 均 为 $300 \mathrm{~W}$ 定电磁辐射器辐射照度 $19 \mathrm{~mW} /$ $\mathrm{cm}^{2}$. 经过这种处理的大豆所含 $\mathrm{Fe}$ 和 $\mathrm{Zn}$ 元 素量的相对改变值可达 $60 \%$. 处理组被检 测的几种微量元素总量与对照组相比, 经统 计学卡方检验有非常显著的差别 $(P<$ 
0.001 ).

司时在透射电镜下对经过电磁辐射处理 后生长的大豆植株细胞的亚显微结构进行了 分析. 与对照组比较发现, 细胞内所含线粒 体数量显著增多. 在某些处理条件下出现线 粒休胀大与破裂现象. 观察与分析组保留样 品生长情况相比较后发现, 经过 $300 \mathrm{~W}$ 定电 磁辐射器辐射照度为 $28 \mathrm{~mW} / \mathrm{cm}^{2}$ 与 $150 \mathrm{~W}$ 定 电磁辐射器辐射照度为 $15 \mathrm{~mW} / \mathrm{cm}^{2}$ 处理的 大豆植株生长旺盛，成熟期较对照组提前约 一个月,话筮大,且数量多.

将样品体内微量元素含量变化、细胞亚
显微结构的改变与保留样品生长情况对照分 析, 我们认为电磁辐射对大豆体内微量元等 的调节作用以及对细胞亚显微结构的影响作 用受到了辐射器材料、辐射温度、辐射照度等 因素的综合制约. 采用适当的辐射波长范围. 的特定电磁辐射, 用适当的辐射照度去处理 生长过程中的大豆,提供了大豆早熟、增产的 又一个新的可能.

石永明

（黑龙江大学,哈尔滨）

尹光初

（黑龙江省农业科学院大豆明究娜，哈尔滨）

\section{从缰核到中脑导水管周围灰质的下行镇痛通路}

本室以往的资料表明，从伏核到中脑导 水管周围灰质 (PAG) 存在一条下行镇痛的 神经通路; 该通路可能以缰核为其中继站,并 证明在缰核内以甲啡肽为其递质. 形态学资 料表明,缰核有神经纤维束直达 PAG. 本工 作探讨缰核与 PAG 之间的功能联系. 在家 兔的缰核和 PAG 内双侧埋植外径 $0.8 \mathrm{~mm}$ 的 不锈钢套管, 通过外径 $0.4 \mathrm{~mm}$ 的注射管用恒 速注射器在 $8 \mathrm{~min}$ (缰核)或 $4 \mathrm{~min}$ (PAG) 内 注入药液 $1 \mu \mathrm{l}$. 用辐射热照射家兔鼻嘴侧部 皮肤，测其甩头反应的潜伏期作为痛反应阈 (简称痛阈), 实验结果用方差分析统计. 每 组用兔 6-10 只.

1. 向家兔一侧缰核内注射吗啡 $10 \mu \mathrm{g}, 20$ $\min$ 后痛阈显著升高,维持时间 $50 \mathrm{~min}$ 以上. 在缰核注射吗啡 $20 \mathrm{~min}$ 后, 向 PAG 内每侧 注人阿片受体阻断剂纳洛酮 (NX) 0.5, 1 或 $2 \mu \mathrm{g}$, 上述吗啡的镇痛作用被不同程度地阻 断, 与 PAG 内注射生理盐水的对照组相比, NX $0.5 \mu \mathrm{g}$ 组的阻断作用不明显 $(P>0.05)$,
而 $\mathrm{NX} 1 \mu \mathrm{g}$ 和 $2 \mu \mathrm{g}$ 组的阻断作用均达显著 水平 $(P<0.05)$. 向缰核内注人生理盐水 $1 \mu 1,20 \mathrm{~min}$ 后在 PAG 内每侧注人 $\mathrm{NX} 2 \mu \mathrm{g}$, 并不引起痛阈显著变化.

2. 在单侧缰核内注射吼啡 $10 \mu \mathrm{g}, 20 \mathrm{~min}$ 后在 PAG 内每侧注入 GABA 受体激动剂; 异鹅墨胺 (muscimol) $0.25 \mu \mathrm{g}$ 㖪 GABA 受体 阻断剂氯甲基荷包牡丹碱 (bicuculliine methochloride） $0.2 \mu \mathrm{g}$. 与 PAG 内注人生理盐 水每侧 $1 \mu \mathrm{l}$ 组相比, 注射异鹅羔胺可明显削 弱细核内注射吗啡所引起的镇痛作用 $(P<$ 0.01 ), 而注射氯甲基荷包牡丹碱则可显著增 强上述吗啡的镇痛效应 $(P<0.05)$.

上述结果提示吗啡可能激活了浯核 到 PAG 的下行镇痛通路, 该通路在 PAG 内涉 及的神经介质可能包括内源性阿片样物质和 GABA.

于龙川 䡛济生 (北京医科大学生理数研空) 